\title{
アルミニウム合金 $\mathrm{AC4CH}$ 大型鋳物の 疲労挙動に及ほす鋳造欠宿の影䈉
}

\author{
田尻明子 ${ }^{* 1}$, 植松美彦 ${ }^{* 2}$, 柿内利文 ${ }^{* 2}$, 野崎大司 ${ }^{* 3}$ \\ 中島正貴 ${ }^{* 4}$, 中村裕紀 ${ }^{* 4}$, 田中 博 ${ }^{* 1}$
}

\section{Effect of casting defect on fatigue behavior in large scale cast aluminium alloy $\mathrm{AC4CH}$}

\author{
Akiko TAJIRI $^{* 5}$, Yoshihiko UEMATSU, Toshifumi KAKIUCHI, \\ Taishi NOZAKI, Masaki NAKAJIMA, Yuki NAKAMURA and Hiroshi TANAKA \\ ${ }^{5}$ Murata Machinery, LTD. Logistics and Automation Division \\ 2 Nakajima, Hashizume, Inuyama-shi, Aichi 484-8502 Japan
}

\begin{abstract}
Several plates had been sampled from a large-scale cast aluminum alloy, $\mathrm{AC} 4 \mathrm{CH}$, ingot. Subsequently, rotating bending fatigue tests and microscopic observation had been conducted using three kinds of specimens with different solidification rates. The shape of pores, hardness and dendrite arm spacing (DAS) were affected by the solidification rates, while the fatigue strengths of three specimens were insensitive to the rates. The lower limit of fatigue strengths were estimated by means of extreme value theory. When separately-located pores were dominant in the specimen, the prediction was inconsistent with test results. The modified counting method of pore size was proposed to improve the accuracy of the prediction.
\end{abstract}

Key Words : Fatigue, Cast aluminium alloy, Casting defect, Gas Porosity, Extreme Value Theory

\section{1. 緒}

近年，エネルギー問題などを背景に低コストで信頼 性の高い設計が要求されており, 軽量で高い比強度を 持ちかつ低コストな鋳造アルミニウム (Al) 合金の利 用拡大が期待されている. 鋳造材は引け巣やガス孔な どの鋳造欠陥を内在しているが，これらの鋳造欠宿は 材料の機械的特性に影響を及ぼす，微小欠陥と疲労強 度との関係については，鉄鋼材料で介在物寸法の Varea から疲労限度 $\sigma_{\mathrm{w}}$ を推定寸る村上らによるV area パラメ 一タモデル (1) がよく知られており，鋳造欠宿を有す る $\mathrm{Al}$ 合金へのこのモデルの適用可能性についても検 討されている ${ }^{(2)}$. しかし, 大型の同一鋳物中での欠 陷分布や疲労強度の部位による相違や相関関係につい ては詳細に研究されていない, 本研究では $\mathrm{Al}$ 合金 $\mathrm{AC4CH}$ 大型鋳物の異なる部位から採取した材料を用 いて疲労試験を行い，主に鋳造時の凝固時間の違いに 起因する鋳造欠陷分布が疲労強度に及ぼす影響にこ注目

\footnotetext{
${ }^{* 1}$ 村田機械（₹484-8502 愛知県犬山市橋爪中島 2)

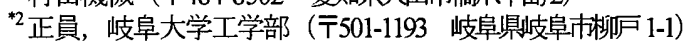

${ }^{3}$ 岐阜大学工学研究科機械ステム工学専攻

*4 正員, 豊田高専 (T471-8525 愛知県豊田市栄生町2-1)

E-mail: yuematsu@gifu-u.ac.jp
}

し, Varea パラメータモデルに基づく疲労限度予測手法 の妥当性について検討した.

\section{2. 供試体およひ実験方法}

$2 \cdot 1$ 供試体および試験片 供試材は $\mathrm{Al}$ 合金 $\mathrm{AC} 4 \mathrm{CH}$ であり, 長さ約 $1.5 \mathrm{~m}$, 幅約 $30 \mathrm{~cm}$ の大型鋳 物である. 材料の化学組成を Table 1 に示す. 予め 鋳物製作時の溶湯流れや冷却凝固を鋳造シミュレ ーションによって予測し，凝固までの時間が異な ることが予測される 3 つの部位から材料を切り出 した。凝固時間が早いものから順に, A 材, B 材, $\mathrm{C}$ 材と呼ぶ. 鋳物型上辺の複数箇所に設置された 湯口に対して, A 材は湯口から最も遠い湯境部, B 材は湯口付近の底部, C 材は湯口直下部にそれぞ れ相当する. 疲労試験片は直径 $8 \mathrm{~mm}$, 長さ $10 \mathrm{~mm}$ の平行ゲージ部を有する回転曲げ疲労試験片であ る. ゲージ部は 2000 番までのエメリ一紙で順次研 磨を施し, バフ研磨により鏡面に仕上げた。

Table 1 Chemical composition of material (wt $\%)$

\begin{tabular}{c|c|c|c|c|c|c}
\hline $\mathrm{Si}$ & $\mathrm{Mg}$ & $\mathrm{Fe}$ & $\mathrm{Ni}$ & $\mathrm{Cr}$ & $\mathrm{Sn}$ & $\mathrm{Al}$ \\
\hline 6.66 & 0.383 & 0.153 & 0.009 & 0.002 & 0.002 & Bal. \\
\hline
\end{tabular}


$2 \cdot 2$ 実験方法 組織観察には塩酸 : $5 \mathrm{ml}$, フッ化水 素酸 : $7.5 \mathrm{ml}$, 蒸留水: $4.5 \mathrm{ml}$ の腐食液を用いて試料表 面を腐食した後, 光学顕微鏡を用いて観察を行った. 硬さ試験にはマイクロビッカース硬さ試験機を用い, 荷重 $0.98 \mathrm{~N}$ ，保持時間 30 秒の条件で試験を行った. 疲 労試験には小野式回転曲げ疲労試験機を用い, 室温大 気中にて繰返し速度 $f=60 \mathrm{~Hz}$ ，応力比 $R=-1$ の条件で試 験を行った. 疲労限度 $\sigma_{\mathrm{w}}$ は, 打ち切り繰返し数 $N=10^{7}$ として定義した.

\section{3. 実 験 結 果}

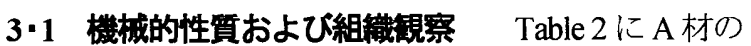
機械的性質を示す. ビッカース硬さは，A，B，C材で それぞれ 116HV，108HV，90HVであった. Fig.1に組 織観察結果を示す。デンドライト組織および鋳造欠陥 が確認される.デンドライトアームスペーシング (DAS) は A，B，C 材の順に大きくなり，それぞれ 平均 $57 \mu \mathrm{m}, 84 \mu \mathrm{m}, 96 \mu \mathrm{m}$ であった. 鋳造欠陥は小寸法 から $1000 \mu \mathrm{m}$ 程度の大寸法まで様々であった。

3.2 疲労強度 Fig.2に $S-N$ 曲線を示す. 疲労強度 は有限寿命域では大きな差は見られない. 疲労限度 $\sigma_{\mathrm{w}}$ は A，B，C材でそれぞれ $65 \mathrm{MPa} ， 80 \mathrm{MPa} ， 75 \mathrm{MPa}$ で あつた.

3.3 破面様相 Fig.3 に A 材の疲労破面の SEM 観 察結果の一例を示す. 表面付近の鋳造欠陥が疲労き裂 の起点であることがわかる．他の材料においてもこれ と同様に, 表面付近の約 $1000 \mu \mathrm{m}$ 前後の鋳造欠陥がき 裂起点となっていた.

Table 2 Mechanical properties of material A

\begin{tabular}{c|c}
\hline $\begin{array}{c}0.2 \% \text { proof } \\
\text { stress } \\
\sigma_{0.2}(\mathrm{MPa})\end{array}$ & $\begin{array}{c}\text { Tensile } \\
\text { stress } \\
\sigma_{\mathrm{B}}(\mathrm{MPa})\end{array}$ \\
\hline 215 & 237 \\
\hline & \\
\hline & \\
\hline
\end{tabular}

(a) material $\mathrm{A}$

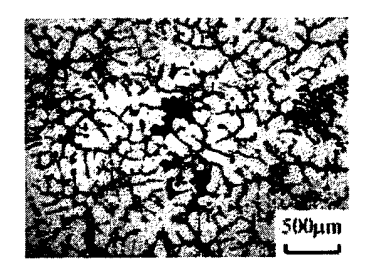

(b) material B

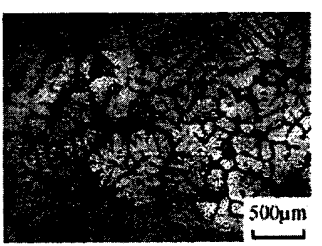

(c) material $\mathrm{C}$
Fig.1 Microstructures of materials.
3 -4 極值統計による area $_{\text {max }}$ の推定および疲労限度

の予測極值統計に基づく手法(1)を用いて，試験片

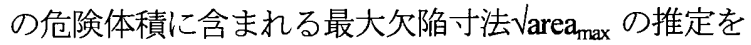
行った．危険体積はゲージ部において公称応力が最大 值の $90 \%$ 以上となる部分とした. Fig.1 に示すように, $\mathrm{A}$ 材と $\mathrm{C}$ 材では大きな欠陷が単独で存在するが， $\mathrm{B}$ 材 では比較的小さな欠陥が密集する場合が多い傾向にあ った。これは試験片採取位置における湯流れや泠却速 度に依存すると考えられる．そこでB材のように小さ い欠陥が密集する場合，村上等が提案する手法に基づ き(1)，欠陷寸法と各欠陷の隣接距離の相対関係から欠 陥を合体させるかどうかを判定し，隣接距離が小さい 場合には結合した仮想的な大欠陥と等価であると考え てVarea を算出した。 その結果， A，B，C 材の最大欠 陥寸法はそれぞれ，956 $\mu \mathrm{m} ， 1512 \mu \mathrm{m}, 1046 \mu \mathrm{m}$ となり， $\mathrm{B}$ 材のみ顕著に大きな欠陥寸法となった.

次にVarea パラメータモデルに基づく下記の推 定式(2)を用いて疲労限度 $\sigma_{\mathrm{w}}$ の推定を行った.

$$
\begin{aligned}
& \sigma_{\mathrm{w}}=\frac{1.43(75+H V)}{(\sqrt{\text { area }})^{1 / 6}} \text { where } \sqrt{\text { area }}<1400 \mu \mathrm{m} \\
& \sigma_{\mathrm{w}}=\frac{1.43(450+H V)}{(\sqrt{\text { area }})^{1 / 3}} \text { where } \sqrt{\text { area }}>1400 \mu \mathrm{m} \text { (2) }
\end{aligned}
$$

ここで，HVはビッカース硬さ，Varea は極值統計の手

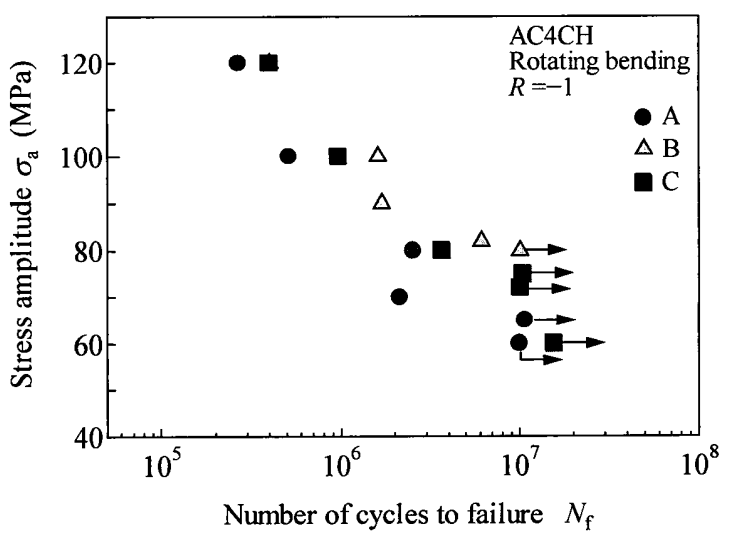

Fig.2 $S$ - $N$ diagram.

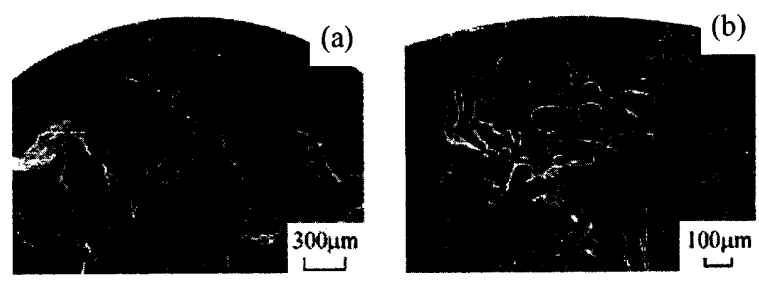

Fig.3 SEM micrographs showing crack initiation site of material A $\left(\sigma_{\mathrm{a}}=120 \mathrm{MPa}, N_{\mathrm{f}}=2.7 \times 10^{5}\right)$ :

(a) low magnification, (b) high magnification. 
法により推定された最大欠陥寸法 $\operatorname{arra}_{\text {max }}(\mu \mathrm{m})$ を用い た. 疲労限度 $\sigma_{\mathrm{w}}$ は，A，B，C材でそれぞれ $87 \mathrm{MPa}$, $70 \mathrm{MPa}, 74 \mathrm{MPa}$ と推定された.

\section{4. 考 察}

Table 3 に各材料の主な特性值と, 疲労限度推定值を まとめて示す. 硬さと DASには凝固時間との相関が見 られ, 凝固時間が早いほど硬さは高く, DAS は小さい. これは鋳造 $\mathrm{Al}$ 合金における一般的な傾向で有る. しか し，予想される最大欠陥寸法については，凝固時間が 中程度のB材で最も大きくなった.

推定疲労限度については，C材については比較的良 い一致を見た． B 材は予想值が低いが，前述のように B 材では複数の欠陥が密集している場合が多く，これ らを合体させて仮想的な大欠陷としため，欠陥寸法を 過大に見積もっている可能性がある. $3 \cdot 4$ 項では Fig.4 に模式的に示すように，比較的近隣にあるI およびII の欠陥郡を合体させた後, I とII距離が II $の$ Varea よ りも小さいため, 最終的にIIIの包絡線を欠陷郡に対す る等価な大欠陥として扱っている. しかし，Fig.4で示 す欠陥郡 I 中の欠陥 $\mathbf{a}$ およびI 中の $\mathbf{b}$ を個々に考えた 場合, 両者の距離は小さい方の欠陥 a の Varea よりも大 きいため, お互いの欠陷は力学的に独立である. そこ で, 近隣する欠陷郡のうち，お互いに最も近い個々の 欠陥が力学的に独立している場合，I とIIの欠陷郡を 個々の欠陥と判定した極值統計結果を Fig.5 に示す. 図

Table 3 Experimental and estimation results of materials.

\begin{tabular}{c|c|c|c|c|c}
\hline \multirow{2}{*}{ Material } & \multirow{2}{*}{$H V$} & \multirow{2}{*}{$\begin{array}{c}\text { DAS } \\
\end{array}$} & \multirow{\mum}{*}{$\begin{array}{c}\text { Varea } \\
(\mu \mathrm{m})\end{array}$} & \multicolumn{2}{|c}{$\sigma_{\mathrm{w}}(\mathrm{MPa})$} \\
\cline { 5 - 6 } & & Varea model & experiment \\
\hline $\mathrm{A}$ & 116 & 57 & 956 & 87 & 65 \\
\hline $\mathrm{B}$ & 108 & 84 & 1512 & 70 & 80 \\
\hline $\mathrm{C}$ & 90 & 96 & 1046 & 74 & 75 \\
\hline
\end{tabular}

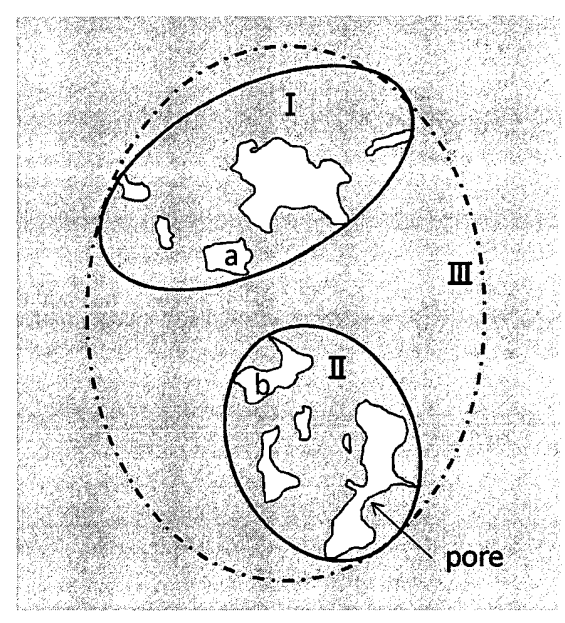

Fig.4 Schematic illustration of coalescence of casting pores.
より，B 材の推定される Varea は $1178 \mu \mathrm{m}$, 対応する予 想疲労限度は $81 \mathrm{MPa}$ となり, 試験結果に近づいた.す なわち, 複数の鋳造欠陥が密集して存在するような場 合，その寸法評価を適切に行わなければ，過度に安全 な設計となる. なお, 同様の手法により $\mathrm{A}$ 材, $\mathrm{C}$ 材の 欠宿寸法を再度推定した場合, $\mathrm{A}$ 材は $943 \mu \mathrm{m}$ とわずか に小さくなるが, C材では $3 \cdot 4$ 項と全く同じ結果とな った.

Fig.5 では，再帰期間から予想される最大欠陥寸法は， 実際の組織観察で得られた最大欠陥よりも小さい. 現 在, 疲労限度を得る際の試験片数を 3 本とし, 再帰期 間を大きくした試験を行っている.

凝固速度の最も速い $\mathrm{A}$ 材の疲労限度については, 予 測值が実験值よりかなり高く, 危険側となっている. $\mathrm{A}$ 材の採取位置は, 大型鋳物で左右の湯口から注ぎ込 まれた溶湯がぶつかり合う湯境にあたり，今後湯境に おける特異な要因がないかを検討する必要がある。

\section{5. 結言}

鋳造 $\mathrm{Al}$ 合金 $\mathrm{AC4CH}$ 大型鋳物材において, 凝固時間 が異なる部位から採取した材料を用いて回転曲げ疲労 試験を行った. その結果, 硬さと DAS には凝固時間と の相関がみられるが，鋳造欠陥の寸法と分布は凝固時 間以外の因子の影響を受けることがわかった. 隣接す る欠陥の結合手法を工夫することで, 鋳造欠陥が密集 するような状態での、年ea パラメータモデルに基づく 疲労限度予測を高精度化することが可能である事を示 した.

\section{参考文献}

（1）村上敬宜，“金属疲労 微小欠陷と介在物の影 響” (2008) 養賢堂.

（2）上野明, 西田匡秀, 宮川進, 山田耕二, 菊池将 二, 第 31 回疲労シンポジウム講演論文集, 159-163 (2012)

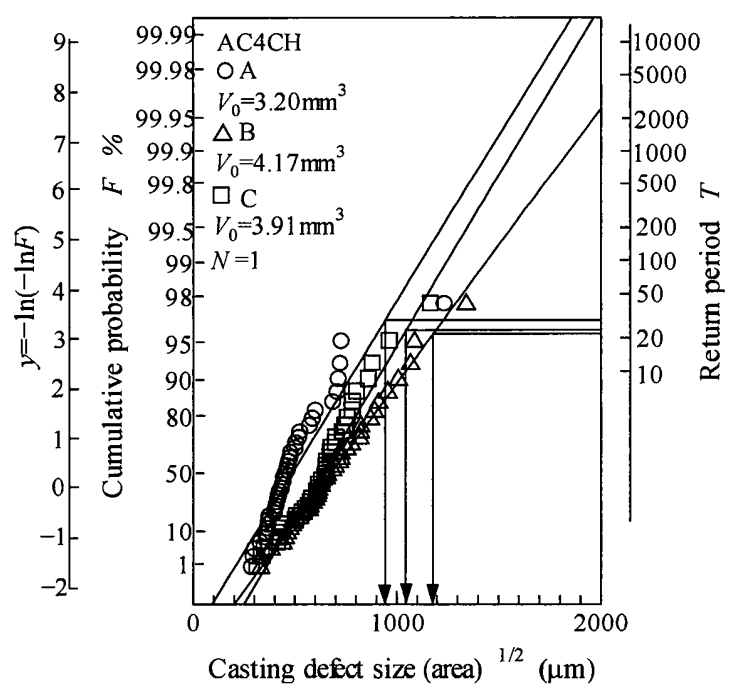

Fig.5 Extreme value distribution of casting defect size. 